4 Abstract

\title{
Retrieval of color producing agents in Case 2 waters using Landsat 8
}

\author{
Javier A. Concha ${ }^{\mathrm{a}, *}$, John R. Schott ${ }^{\mathrm{a}}$ \\ ${ }^{a}$ Rochester Institute of Technology (RIT), NY 14623, USA
}

New approaches need to be considered to solve the current high demand for color producing agent (CPA) retrievals over inland and coastal waters (Case 2 waters). Traditional retrieval algorithms are known to fail over highly turbid Case 2 waters because they were developed specifically for the open ocean (Case 1 waters). Landsat 8 provides an improved signal-to-noise ratio (SNR) and a new spectral coastal aerosol band in the blue. This additional information provides means to tackle this retrieval endeavor. A look-up-table (LUT) and spectrum-matching methodology was implemented to simultaneously retrieve CPAs, taking advantage of Landsat 8's new features. A LUT of spectral remote-sensing reflectances $\left(R_{r s}\right)$ with different concentration of CPAs was produced using the in-water radiative transfer model Hydrolight. A model-based empirical line method (MoB-ELM) algorithm was developed to atmospherically correct the Landsat 8 imagery and allow direct comparison with the LUT of $R_{r s}$. This MoB-ELM atmospheric correction algorithm uses pseudo-invariant features (PIFs) from the image, ground-truth data and the Hydrolight model. The retrieval algorithm was applied over three Landsat 8 scenes and shows a normalized root mean squared error (NRMSE) of about $14 \%$ for Chlorophyll- $a, 11 \%$ for total suspended solids (TSS), and 7\% for colored dissolved organic matter (CDOM) when compared with ground-truth data. The CPA concentration maps exhibit expected trends of low concentrations in clear water and higher concentrations in turbid water.

These results demonstrate that the developed algorithm allows the simultaneous mapping of concentration of all CPAs in Case 2 waters and over areas where the traditional algorithms fail or are not available due to spatial resolution. Therefore, this study shows that the Landsat 8 satellite can be utilized over Case 2 waters as long as a careful atmospheric correction is applied.

Keywords: Landsat 8, color producing agents, CPAs, Case 2 Waters, retrieval 


\section{Introduction}

The launching of a new generation of high spatial resolution satellites (e.g. Landsat 8, Sentinel 2 ) is opening a complete new era in the remote sensing of coastal and inland waters. New sensor specifications could meet the requirements needed to have available the same kinds of tools (e.g. Chl- $a$ product) that the first generation of ocean color satellites, such as the Moderate Resolution Imaging Spectroradiometer (MODIS) (Esaias et al., 1998) and the Sea-viewing Wide Field-of-view Sensor (SeaWiFS) (McClain et al., 2004), made available for open ocean science more than a decade and half ago. The hope is to have these tools for coastal and inland waters available at a global scale and on a regular basis, similar to MODIS capabilities for open oceans. Although Landsat 8 does not have a daily frequency as MODIS does, it could definitely contribute to this endeavor, and most importantly, it prepares the way for future missions with similar spatial resolution specifications (e.g. Sentinel 2, Hyperspectral Infrared Imager (HyspIRI)).

The retrieval of color producing agents (CPA) (chlorophyll-a, sediments (or total suspended solid (TSS)) and colored dissolved organic matter (CDOM)) is in general performed in the reflectance domain, so the very first step is to perform a high quality atmospheric correction (a.k.a. atmospheric compensation) to convert the image from the satellite from radiance units to reflectance units. To perform an accurate atmospheric correction over water is extremely complex since most of the signal reaching the sensor is due to atmospheric scattering and surface reflected signal, with only a small fraction due to the signal of interest, the water-leaving signal. Therefore, it is important to perform a rigorous atmospheric correction.

Most of the atmospheric correction algorithms for open oceans (Case 1 waters) are based on the methods developed for ocean color satellites by Gordon (1997). These methods are based on the fact that the signal leaving the water does not contribute to the overall signal beyond the near infrared (NIR) part of the spectrum; so the signal reaching the sensor is caused only by atmospheric scattering (Gordon \& Wang, 1994). This is known as the black pixel assumption. This concept can

${ }^{*}$ Corresponding author at: Digital Imaging and Remote Sensing Laboratory, Chester F. Carlson Center for Imaging Science, Rochester Institute of Technology, 54 Lomb Memorial Dr., Rochester, NY 14623, USA. Tel.: +1 5852903145 .

Email address: jxc4005@rit.edu (Javier A. Concha) 
be expanded to the short wave infrared (SWIR) bands when the black pixel assumption is not valid in the NIR bands, which is the case for Case 2 and highly productive Case 1 waters (Wang, 2007). Unfortunately, most of these methods are not suitable for highly turbid coastal water, although different modifications to these algorithms have been suggested (Patt et al., 2003).

The Landsat program has been monitoring the earth for more than four decades, being the longest uninterrupted data set available. The Landsat satellites' main mission is to image the land areas of the earth, therefore, there are typically few images available for open oceans. This is one of the reasons why Landsat satellites have been underutilized by the ocean color community for the study of water bodies. In addition, the Landsat instruments have generally had broad bands and a low signal-to-noise ratio (SNR) when compared to ocean color satellites such as SeaWiFS and MODIS. However, Landsat 8 could fulfill a niche in the ocean color community for coastal and inland water body studies where a $1000 \mathrm{~m}$ spatial resolution is not suitable. This is where Landsat 8 has a valuable potential for water quality studies in more optically complex water bodies (Case 2 or high productive Case 1 waters).

Landsat 8 is the newest generation of Landsat satellites with two state-of-the-art instruments pnboard, the Operational Land Imager (OLI) and the Thermal InfraRed Scanner (TIRS) (Irons et al. 2012). With its 12-bit quantization and improved SNR, OLI is a big improvement to the Landsat mission. In addition, OLI includes a new coastal aerosol band (Band 1: $443 \mathrm{~nm}$ ) that increased the spectral resolution of the instrument. These improvements are the main drivers for the hypothesis that the Landsat 8 satellite will have a better performance in water quality studies than its predecessors. Roy et al. (2014) stated this potential use of Landsat 8 for fresh and coastal water studies, mainly due to a reported SNR that exceeded expectations and the new coastal band.

Gerace et al. (2013) demonstrated that the spectral coverage and radiometric resolution of OLI should dramatically improve our ability to simultaneously retrieve the CPA's concentration from water bodies. Vanhellemont \& Ruddick (2014) and Vanhellemont \& Ruddick (2015) created a tool to apply the standard algorithm for atmospheric correction over water developed by Gordon \& Wang (1994) to Landsat 8 over turbid and extremely turbid waters. In Vanhellemont \& Ruddick (2015), after atmospheric correction, they used the end product for detection of high concentra- 
tions of black sediments, but neither concentration values nor comparison with field measurements were reported. Franz et al. (2015) describes an implementation of the atmospheric corrections developed by Gordon \& Wang (1994) applied to Landsat 8 in the SeaWiFS Data Analysis System (SeaDAS) software package (URL: http://seadas.gsfc.nasa.gov/). A comparison of the Landsat 8's retrieved $R_{r s}$ and chlorophyll- $a$ concentration over Chesapeake Bay with results from MODIS, SeaWiFS and in situ historical chlorophyll- $a$ measurements is presented showing a relatively good agreement. Though again, no direct comparison to simultaneously measured values were available.

We developed a process to retrieve CPAs from Landsat 8 imagery over Case 2 waters that includes inland and coastal water. The retrieval algorithm compares water remote-sensing reflectance $\left(R_{r s}\right)$ spectra with unknown concentrations to $R_{r s}$ spectra in a look-up-table (LUT) built using known concentrations. The area of study chosen for this work was the Rochester Embayment, Rochester, NY (latitude: $43^{\circ} 18^{\prime} \mathrm{N}$ and longitude: $76^{\circ} 42^{\prime} \mathrm{W}$ ). An example of a Landsat 8 image showing this area of study is illustrated in Figure 1. This Landsat 8 image was taken on September 19, 2013 (scene LC80160302013262LGN00). This area includes Lake Ontario, the Genesee River and river discharge, Irondequoit Bay and some nearby ponds (Long Pond and Cranberry Pond). These water bodies have experienced degraded water quality in the past two decades, reducing their recreational and aesthetic value, being designated as an Area of Concern (Makarewicz, 2000). This area of study was chosen because of the very wide range of constituents between the ponds and the open water in the lake, which provides a very challenging case for the retrieval. Long and Cranberry Ponds are considered hypereutrophic waters with high levels of nutrients, mainly due to a very high concentration of total phosphorus and chlorophyll- $a$ (NYSDEC, 2010; Makarewicz \& Lampman, 1994) while Irondequoit Bay is considered eutrophic (Makarewicz, 2000). The Genesee River contributes with nutrient and sediment discharges over the Rochester Embayment, being the second largest tributary loading of phosphorus to Lake Ontario (NYSDEC, 2015). Lake Ontario is the forth largest in volume of the Great Lakes and it is classified as an oligomesotrophic lake (IJC, 1980). 


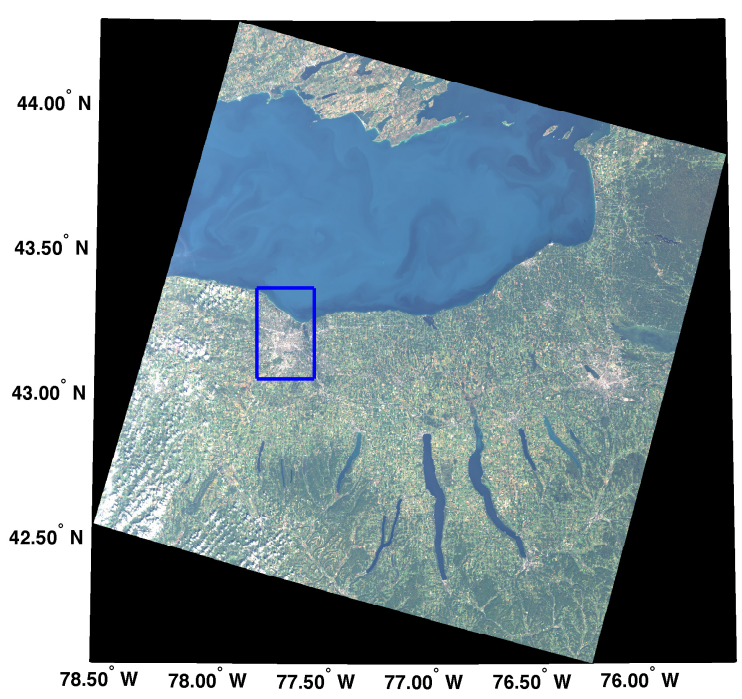

(a)

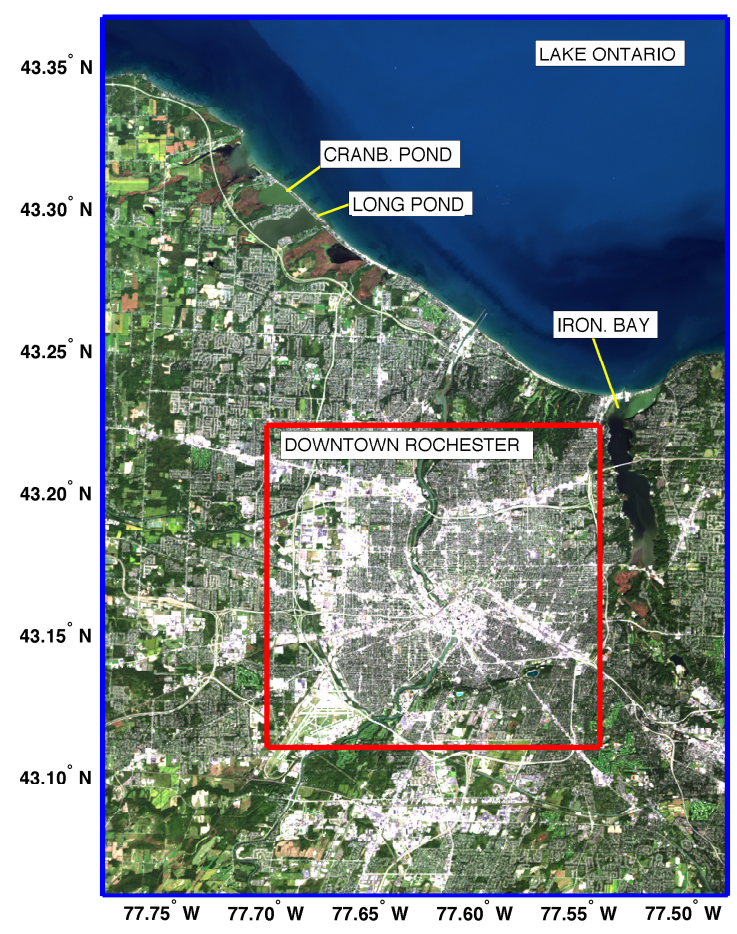

(b)

Figure 1: Landsat 8 image (scene LC80160302013262LGN00) acquired 09-19-2013 (a), with zoom over study region (b) showing the downtown of Rochester, NY and the Rochester Embayment. 


\section{Methods}

\subsection{Retrieval Process Overview}

The retrieval process described in this work was first introduced by Concha \& Schott (2014b) and Concha (2015) and is based on previous work done by Raqueño et al. (2000), Gerace \& Schott (2012), Pahlevan et al. (2012) and Gerace et al. (2013). A flow diagram of the process is illustrated in Figure 2, In short, the retrieval process works as follows. First, the radiance image from the satellite is atmospherically corrected and transformed to $R_{r s}$ spectra, as shown in the diagram. At this point the $R_{r s}$ spectra of water pixels in the scene with unknown CPAs concentrations are compared with a LUT of $R_{r s}$ spectra with known CPA concentrations. This comparison is made by using a spectrum-matching technique (Raqueño et al., 2000; Mobley et al., 2005) that calculates the root mean squared error (RMSE) to find the closest match in the LUT. The end products are maps of CPAs concentrations (see Figure 2). Each step in this retrieval process is described in more detail below.

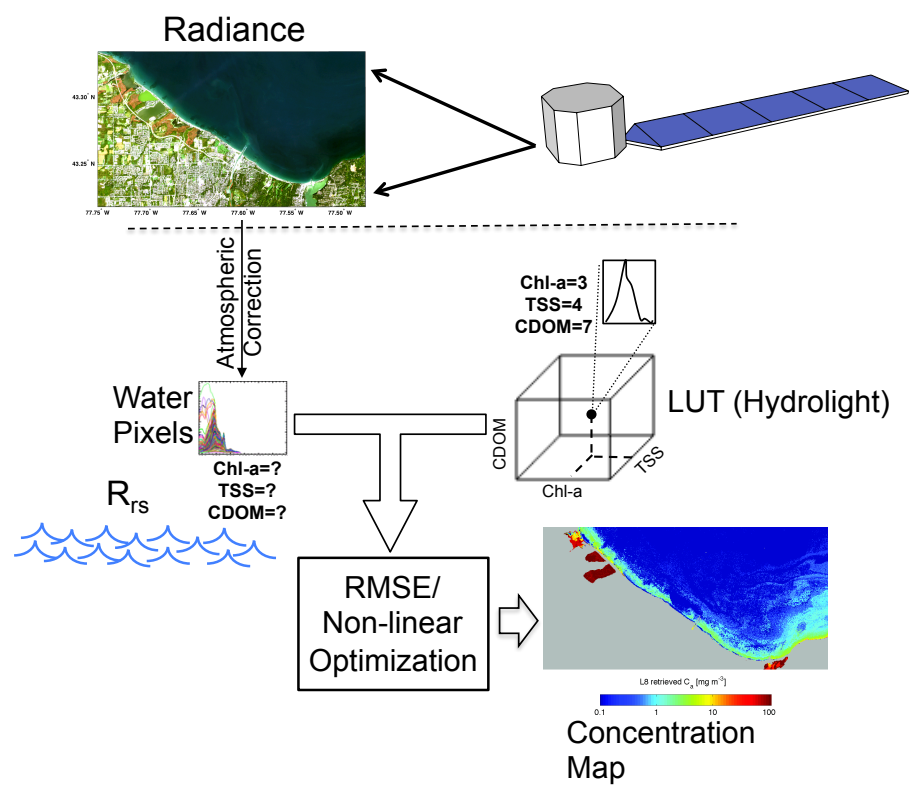

Figure 2: Retrieval process flow diagram. The radiance image from the satellite is first corrected for atmospheric effects, having as result $R_{r s}$ spectra for each water pixel in the image. Then, a spectrum-matching methodology is used to find the closest match in the least-squared sense for the water pixels with unknown CPAs concentration in the LUT of water pixels with known CPAs concentration. The final result is a concentration map for each CPA. 


\subsection{The MoB-ELM Atmospheric Correction}

An overview of the atmospheric correction method used in the work is described by Concha \& Schott (2014a), and it is explained in more detail in this paper. This is a model-based empirical line method (MoB-ELM) based on the work done for simulated OLI data by Gerace \& Schott (2012). The MoB-ELM atmospheric correction is a modified version of the traditional empirical line method (ELM) (a.k.a. empirical line fit or ELF). The ELM atmospheric correction method uses at least two pixels from the scene with known reflectance values (Schott, 1997). It assumes that there is a linear relationship between the radiance values from the image and the reflectance values from ground-truth data. Therefore, the ELM method consists of solving the following linear equation:

$$
L=m \cdot R_{r s}+b
$$

where $L$ is the radiance reaching the sensor, $m$ is the slope of the line, $R_{r s}$ is the remote-sensing reflectance of the target, and $b=L_{u}$ is the y-intercept, with $L_{u}$ being the upwelled radiance (a.k.a. path radiance). $L$ and $R_{r s}$ in Equation 1 are the known radiance values from the image and the ground-truth data from the field, respectively. In order to solve for the unknown $m$ and $b$ values in Equation 1, at least two pixels are needed. These two pixels are known as the bright and dark pixels because they are chosen from a bright and dark object in the scene in order to represent the whole range of values in the scene. The concept behind the traditional ELM is illustrated in Figure 3 showing a plot of $R_{r s}$ versus radiance $L$ values for the $i t h$ band, $B a n d_{i}$. This linear equation is solved for each band independently. After $m$ and $b$ have been determined, the $R_{r s}$ of each water pixel in each band can be calculated from its $L$ value in the image using $R_{r s}=(L-b) / m$. Note that the ELM assumes that the atmosphere is uniform across the region of the image over which it is applied, and the images need to be checked for haze and atmospheric uniformity over the area of study. This is accomplished by checking visually if the SWIR 2 band and band 9 (cirrus band) look uniform over the area of study.

The bright and dark objects in the scene need to be approximately uniform over at least 3-by-3 pixels (Schott, 1997). This means that for the spatial resolution of Landsat 8, these objects have 


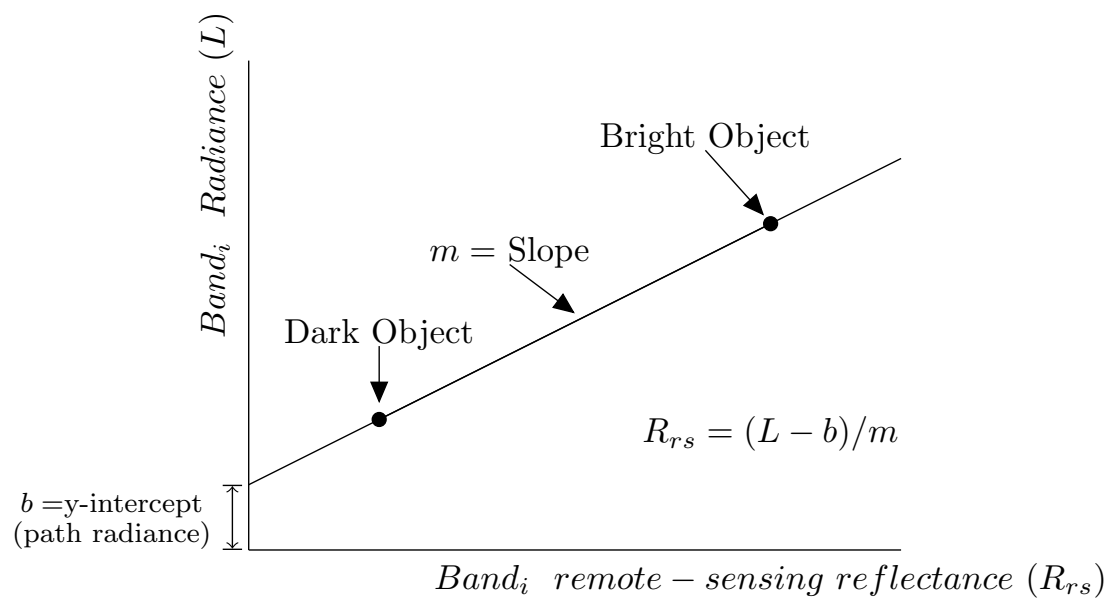

Figure 3: Traditional ELM. Two pixels from the image, the bright and dark pixel, are used to solve a linear equation with a slope $m$ and y-intercept $b$ in the $R_{r s}, L$ space. Once this relationship is established, each $L$ value in the image can be converted to $R_{r s}$ through $R_{r s}=(L-b) / m$.

to be at least $90 \times 90$ meters. This requirement is not always feasible. Additionally, it is not always possible to have ground-truth reflectance data in every satellite overpass. The MoB-ELM avoids the need for ground-truth reflectance collection at each overpass by using pseudo-invariant features (PIFs) in the scene as the bright object and a $R_{r s}$ value from the physics-based numerical model for water, Hydrolight, for the dark object. The following sections describe the way the $L$ and $R_{r s}$ values for these two pixels are determined.

\subsubsection{Bright Pixel Determination}

The MoB-ELM method uses pseudo-invariant features (PIF) extraction to determine the bright pixel from the Landsat 8 image. PIFs are features in the scene that do not change their reflectivity properties drastically over time. Urban features could be considered as PIFs, and therefore, this extraction is applied over an urban area within the image. The downtown of Rochester, NY was selected as the urban area in our case (Figure 1). We created a PIF mask following the PIF extraction method described by Schott et al. (1988) in order to isolate the PIFs in the Landsat 8 image. A flow diagram describing this PIF extraction method is illustrated in Figure 4, This extraction method takes advantage of two facts. The first is that water is highly absorbent in the SWIR, which makes water a dark target beyond the NIR wavelengths, i.e. water has low values when compared with urban features and vegetation in the NIR. The second fact is that vegetation 
has a high value in the NIR when compared with the red (red edge). Therefore, a ratio between the NIR band and the red band has a high value for vegetation and a low value for urban features and water.

The steps for the PIF extraction are the following:

1. A mask that accepts the urban features and vegetation, and rejects water is created (represented as Urban ON, Veget. ON and Water OFF in the left arm of Figure 4). To accomplish this, the second short wave infrared band (SWIR 2) of Landsat 8 is used. A threshold is selected so that the water pixels are masked off. The threshold is determined visually by varying its value until all water pixels are masked.

2. A mask that accepts the urban features and water, and rejects vegetation is created (represented as Urban ON, Veget. OFF and Water ON in the right arm of Figure 4). To accomplish this, the ratio between the NIR band and red band of Landsat 8 is thresholded so that the high values for vegetation are rejected. The threshold value is determined in a similar fashion to step 1 .

3. The previous two masks are combined using a logic .AND. gate, as shown in Figure 4 , creating a "PIF mask" that rejects the vegetation and water, and only accepts the urban features.

4. The PIF mask is applied to the image, obtaining the PIF image as the result.

Note that the urban features could change from one acquisition time to another, and therefore, the PIF mask should only include the features that are similar over time. Therefore, a total of seven PIF masks from Landsat 8 scenes with clear sky conditions were combined to create a master PIF mask by applying a logic .AND. gate.

The master PIF mask is utilized to determine both the radiance and reflectance value of the bright pixel from the urban features of downtown Rochester. The radiance values of the bright pixel are obtained by applying the PIF mask directly to the particular radiance Landsat 8 image and averaging the values that pass through the mask. The reflectance values of the bright pixel are obtained by applying the master PIF mask to the "Provisional Landsat 8 Surface Reflectance 


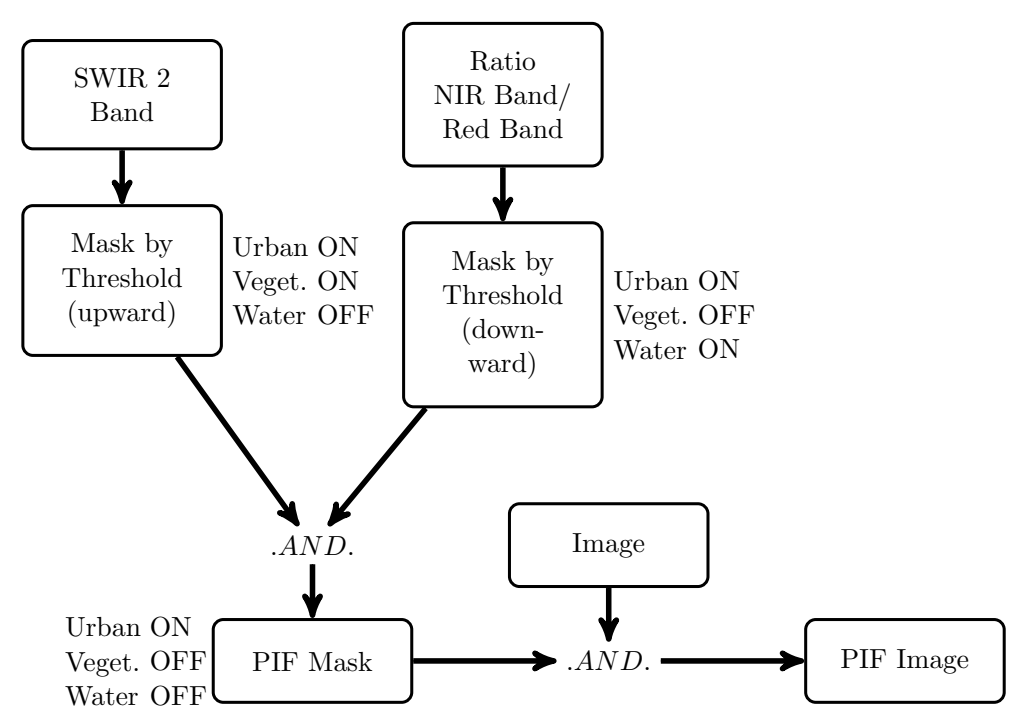

Figure 4: Flow chart for the PIF extraction method. Two mask are created. The first one rejects water pixel. The second mask rejects vegetation. The end mask, named PIF mask, is a combination of both previous masks that only accepts the urban features.

product" corresponding to the particular Landsat 8 image to be used to perform the retrieval of CPAs. The Provisional Landsat 8 Surface Reflectance product is distributed by the U.S. Geological Survey (USGS) and generated from a specialized software called L8SR (for more info about this product see USGS (2015)). Figure 5 shows a false color image (R: NIR band, G: Red band B: Green band) of downtown Rochester, NY (a) and the master PIF mask applied to this image (b). Note that only the urban features are shown in (b), and the rest of the pixels are masked off (black pixels). Note that the provisional Landsat 8 reflectance product was used to extract information of the urban features and not of the water itself.

Once the master PIF mask is applied to the Provisional Landsat 8 Surface Reflectance product for the particular Landsat 8 image, the statistics are calculated including all of the PIF pixels and the mean value for each band is used as the reflectance value of the bright pixels. Finally, the reflectance values are divided by $\pi$ in order to have the same units as $R_{r s}$ (i.e. BRDF values $\left[s r^{-1}\right]$ ). Figure 6 shows an example of radiance value (a) and the $R_{r s}$ value (b) for the bright pixel (solid line) in a Landsat 8 scene.

A different approach that uses a bright target from the water pixels in the scene instead of the urban features (i.e. PIFs) was also evaluated. An example of this pixel could be the most 


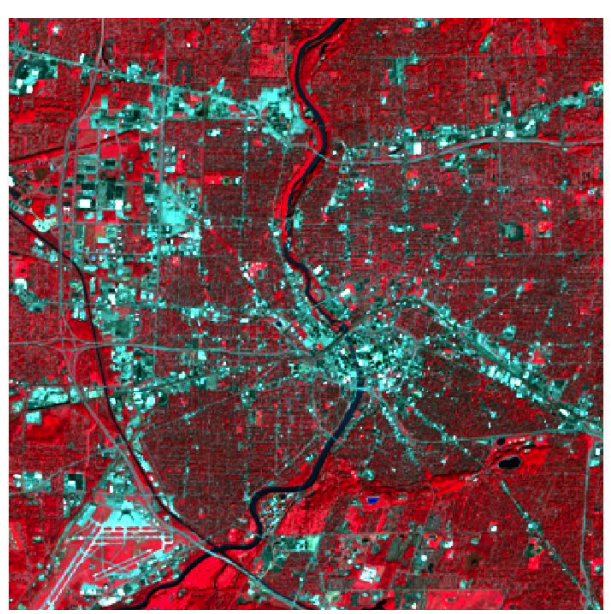

(a)

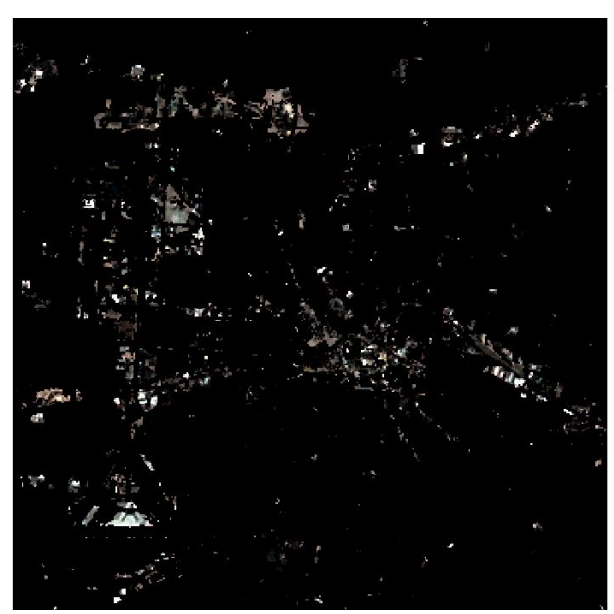

(b)

Figure 5: PIF mask determination. (a) False color image (R: NIR band, G: Red band B: Green band), with vegetation in red and (b) PIF mask over downtown Rochester.

eutrophic pond in the scene. The $R_{r s}$ of this bright pixel is generated in Ecolight using IOPs and concentrations from the field. Then, the radiance value of this bright pixel is obtained from the corresponding region in the Landsat 8 radiance image. This approach is attractive when a wide range of water quality conditions are present and concentration measurements are available of bright and dark water targets. This approach may improve results where glint is present as it compensates for not only atmospheric effects but any other approximately linear phenomena that would modify the reflected energy leaving the water volume. An explanation of how Ecolight is utilized to generate the spectral $R_{r s}$ of a water pixel can be found in the following section.

\subsubsection{Black Pixel Determination}

The Landsat surface reflectance product cannot be used for the dark pixel target because the product is not precise enough over water. Therefore, the $R_{r s}$ spectra for the dark pixel target is obtained from the Ecolight model, which is a special version of the Hydrolight model that runs faster. The Hydrolight model is a radiative transfer numerical model that computes radiance distribution and derived quantities (e.g. $R_{r s}$ ) for natural water bodies (Mobley \& Sundman, 2013b). The view angle of interest for this work is only the nadir angle, and therefore, Ecolight is a more convenient option. It is suggested to use the Ecolight model when only the nadir-viewing $R_{r s}$ is needed since the Ecolight model only solves the azimuthal averaged version of the radiative 


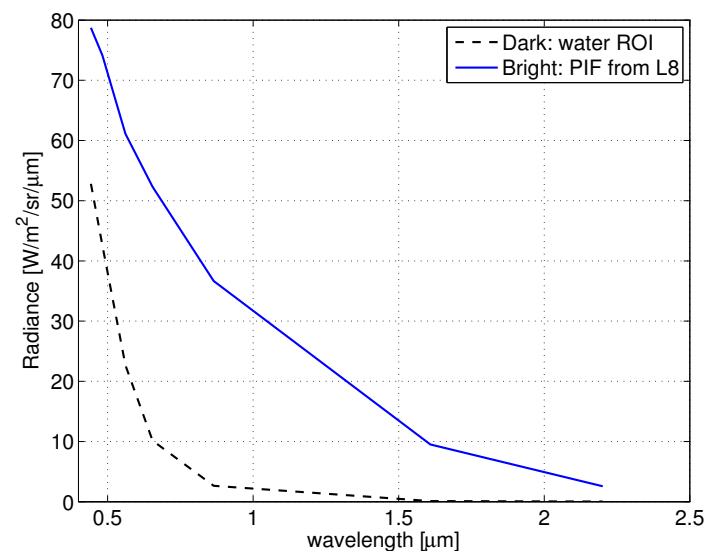

(a)

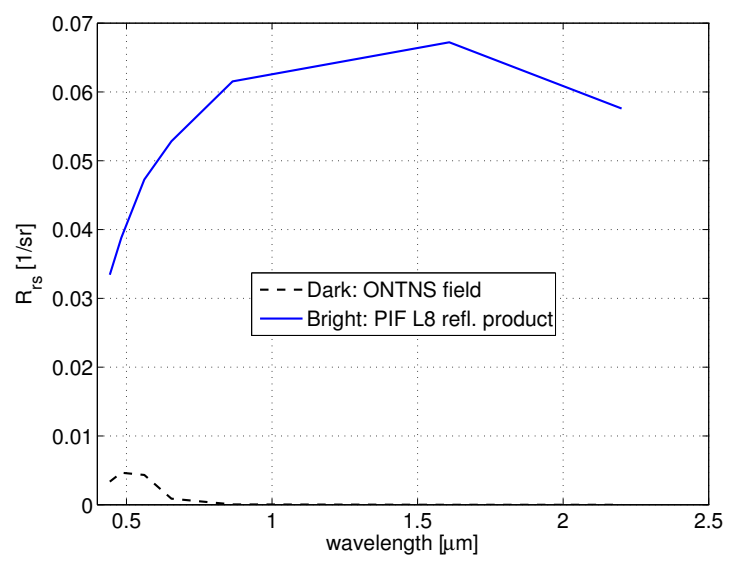

(b)

Figure 6: Example of the bright and dark pixel used in the MoB-ELM atmospheric correction method for Landsat 8 scene acquired on 09-19-2013.

transfer equation (RTE). Solving only the azimuthal average version of the RTE requires much less computer time than solving the RTE for all azimuthal directions to have the full radiance distribution as in Hydrolight (Mobley \& Sundman, 2013b). Note that Ecolight uses exactly the same inputs as Hydrolight.

The dark pixel is taken from a region of interest (ROI) over water present in the Landsat 8 radiance image with a low concentration of CPAs. It is worth mentioning that this dark pixel is not necessarily the darkest pixel in the scene nor one with zero reflectance. Inherent optical properties (IOPs) and CPA concentration measurements taken in the field (or estimated from ancillary sources) for the same ROI are input to Ecolight. The field and lab measurements are described in the Results and Discussion section (Section 3) below. The "Case 2 model" in Ecolight is used to generate a $R_{r s}$ spectra for the dark pixel to be used in the MoB-ELM method. This Case 2 model is a generic four-component (pure water, chlorophyll-bearing particles, CDOM, and mineral particles) IOP model (Mobley \& Sundman, 2013a). Concentration, phase function, and mass-specific absorption and scattering coefficient spectra for each CPA need to be input separately in the Case 2 model of Ecolight. In this study, instead of using the term mineral particles, which only includes inorganic particles, we used the term suspended matter (SM) to account for both organic and inorganic particles. The reason for this is that the suspended particles were not treated 
separately as organic or inorganic in the lab measurements.

An example of the inputs used to generate the $R_{r s}$ spectra of the dark pixel for a particular date is specified below. Table 1 shows the CPAs concentrations for two different water samples from the stations of the data collection on September, 19th, 2013. The location of these stations is shown in Figure 7. These water samples were collected near the shore of Lake Ontario (labeled as ONTNS) and from the southern part of Long Pond (labeled as LONGS), and they represent two scenarios with totally different concentrations of CPAs. The concentration of CPAs are chlorophyll- $a$ concentration, $C_{a}\left[\mathrm{mg} \mathrm{m}^{-3}\right]$, total suspended solids concentration, TSS $\left[\mathrm{g} \mathrm{m}^{-3}\right]$ (a.k.a. suspended particulate matter (SPM) or suspended matter (SM) concentration), and CDOM absorption coefficient at $\lambda_{0}=440 \mathrm{~nm}, a_{C D O M}\left(\lambda_{0}=440 \mathrm{~nm}\right)[1 / \mathrm{m}]$. The water sample ONTNS was used to generate the reflectance spectra for the dark pixel in Ecolight since it exhibits a low concentration of CPAs. The concentrations for each component were set to be constant with depth in Ecolight with the values obtained from field measurements shown in Table 1

Table 1: CPA concentrations of the water samples collected for two stations on the 09-19-2013 collection (Figure 7) used as input in Ecolight (Labels: ONTNS: Lake Ontario near-shore and LONGS: Long Pond south).

\begin{tabular}{c|c|c|c} 
Station & $\begin{array}{c}C_{a} \\
{\left[\mathrm{~m} \mathrm{~m}^{-3}\right]}\end{array}$ & $\begin{array}{c}\text { TSS } \\
{\left[\mathrm{g} \mathrm{m}^{-3}\right]}\end{array}$ & $\begin{array}{c}a_{C D O M}\left(\lambda_{0}=440 \mathrm{~nm}\right) \\
{[1 / \mathrm{m}]}\end{array}$ \\
\hline \hline ONTNS & 0.48 & 1.6 & 0.1151 \\
LONGS & 112.76 & 46.0 & 1.1953
\end{tabular}

The absorption properties for the component chlorophyll- $a$ were input by user-supplied data files containing mass-specific absorption coefficients as a function of wavelength. This mass-specific absorption spectra is shown in Figure 8,(a). These data were obtained from lab measurements of absorption coefficient spectra for the water sample ONTNS with a spectrophotometric method following SeaWiFS protocols (Mueller \& Austin, 1995). The spectrophotometric method yields absorption coefficients, which are converted to mass-specific absorption coefficients by dividing the absorption coefficients spectra by its concentration $\left(C_{a}\right)$. This $C_{a}$ was determined in lab by a spectrophotometric method as well. For the chlorophyll- $a$ scattering properties, the same massspecific scattering coefficient data used in Raqueño et al. (2000) and Raqueño (2003) were utilized. These data were characterized through laboratory studies as part of a data collection on May 20, 1999 over the same area of study. These data were used because no current scattering measurements 


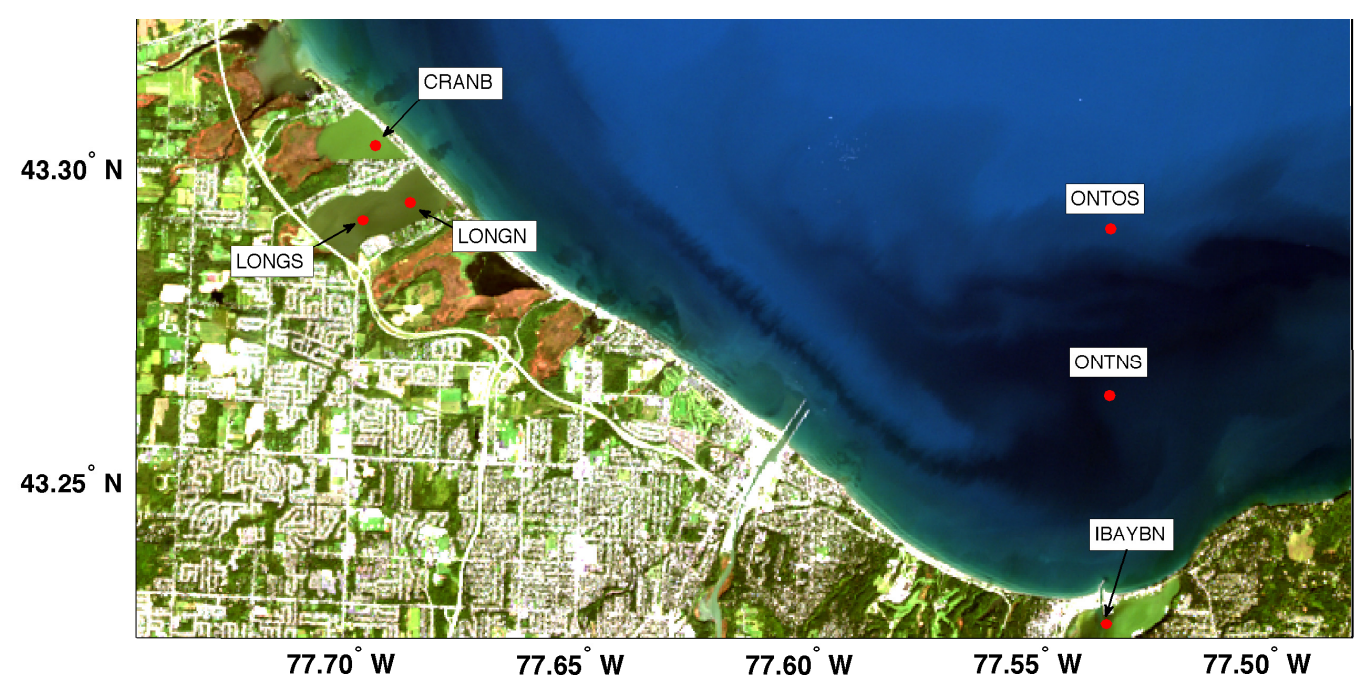

Figure 7: Landsat 8 scene acquired on 09-19-2013 (scene LC80160302013262LGN00) showing the sites in the Rochester Embayment for the water sample collection. (Labels: ONTNS: Lake Ontario near-shore, ONTOS: Lake Ontario off-shore, LONGS: Long Pond south, LONGN: Long Pond north, CRANB: Cranberry Pond and IBAYN: Irondequoit Bay north)

were available over the area of study. These data are shown in Figure 8.(b). A Fournier-Forand (FF) phase function with a backscatter fraction of 0.010 was selected as the scattering phase function for chlorophyll- $a$. The details about the selection of this specific phase function will be described below.

For the CDOM component, the absorption specification $a_{C D O M}(\lambda)$ was input following the format required by Ecolight. First, the absorption coefficients were determined by spectrophotometric lab measurements for the ONTNS water sample. These data are shown in Figure 8, (c). Then, the data were normalized by the absorption value $a\left(\lambda_{0}\right)=0.1151[1 / m]$ at the reference wavelength $\lambda_{0}=440 \mathrm{~nm}$, so that $a^{*}\left(\lambda_{0}\right)=1$. These normalized data are shown in Figure 8. (d) as purple dots. An exponential curve with the following equation

$$
a^{*}(\lambda)=a^{*}\left(\lambda_{0}\right) \exp \left[-\gamma\left(\lambda-\lambda_{0}\right)\right]
$$

was fitted to the normalized data. It was determined that the decay constant $\gamma=0.0126$. The fitted curve is illustrated in Figure 8. (d) as a solid line. The parameters of this fitted curve are input into Ecolight to specify the CDOM normalized mass-specific absorption $a^{*}$, and $a\left(\lambda_{0}\right)=0.1151[1 / m]$ to specify the CDOM absorption coefficient at the reference wavelength $\lambda_{0}=440 \mathrm{~nm}$. 
The SM mass-specific absorption coefficient was determined in the same fashion as for the chlorophyll mass-specific absorption coefficient from lab measurements of the ONTNS water sample. The SM mass-specific absorption coefficients are shown in Figure 8. (e). The SM mass-specific scattering coefficients are the same used by Raqueño et al. (2000) and Raqueño (2003) for the same area of study and are shown in Figure 8.(f). An FF phase function with backscatter fraction 0.010 was selected as the scattering phase function for the SM. The details about the selection of this specific phase function will be described below.

One of the input parameters needed by Ecolight is the scattering phase function for each component. Ecolight includes by default discretized Fournier-Forand phase function for given backscatter fraction values, $b_{b} / b$, where $b$ is the total scattering coefficient (for all directions) and $b_{b}$ is the scattering coefficient only in the backward direction. $b_{b} / b$ could have discretized values between 0.0001 and 0.50 (i.e. [0.01\%-50\%]). There was no empirical information available about $b_{b} / b$ so the following approach was used to estimate the scattering phase function for both the chlorophyll- $a$ and the SM components. A LUT of $R_{r s}$ with different scattering phase functions was created in the following fashion: one Ecolight run was obtained for each discretized Fournier-Forand phase functions from the library of phase functions supplied with Ecolight 5.2, but maintained the rest of the input parameters to Ecolight the same, i.e. concentrations, IOPs, surface and bottom boundary conditions, atmospheric conditions, and geometry. These parameters correspond to the ONTNS water sample described above. The different $R_{r s}$ spectra in the LUT were compared with the $R_{r s}$ for ONTNS measured in situ. The best match was determined by choosing the lowest root mean squared error (RMSE) between the $R_{r s}$ for the ONTNS water sample measured in situ and the simulated $R_{r s}$ spectra for the ONTNS water sample. It was determined that the best match corresponds to the $R_{r s}$ in the LUT generated with a discretized Fournier-Forand phase function with a backscatter equal to 0.010, i.e. $1 \%$ of backscatter fraction (file name: FFbb010.dpf).

The following parameters were input to Ecolight in order to simulate the Landsat 8 acquisition conditions. The illumination conditions were input to Ecolight by specifying the solar zenith angle and day of the year that matched the Landsat 8 image. Internal sources and inelastic scatter were not included in the simulations, as we did not have this information. The wavelength range 
was $[400 \mathrm{~nm}, 1000 \mathrm{~nm}]$, with a $5 \mathrm{~nm}$ step, i.e. 120 wavelengths. Default values for the air-water surface conditions were used, with a windspeed equal to $5 \mathrm{~m} / \mathrm{s}$, a real index of refraction equal to $n=1.34$, and the semi-empirical sky model (based on RADTRAN-X). Recall that Hydrolight uses a Cox-Munk air-water surface model that parameterizes gravity and capillary waves via the wind speed (Mobley \& Sundman, 2013a). Finally, the bottom boundary condition used in Ecolight was "the water column is infinitely deep."

Ecolight is run once with all the inputs described above and the spectral $R_{r s}$ for the dark pixel is obtained. This spectral $R_{r s}$ is a function of 120 wavelengths, and therefore, it needs to be spectrally sampled to the OLI's band-averaged relative spectral response (RSR) to obtain the values for the OLI's eight bands. Figure 6,(b) shows this $R_{r s}$ spectra as a black dashed line. Using a $R_{r s}$ generated in Ecolight (i.e. a model-based dark pixel) instead of an in situ dark target in the MoB-ELM helps account for differences between atmospheric correction and the Hydrolight-based LUT used for retrieving the CPA concentrations (explained in the following Section 2.3).

The radiance spectra for the dark pixel is obtained from an ROI in the Landsat 8 radiance image that includes the ONTNS station. Statistics are computed in this dark region, and the mean values in each band is used as the radiance spectra for the dark pixel. This radiance spectra for the dark pixel is shown in Figure 6. (a) as a black dashed line.

As a review, Figure 6 shows the different spectra used to perform the MoB-ELM atmospheric correction method, where four different spectra can be seen: one $R_{r s}$ and one radiance spectra for the bright pixel (obtained using the PIF extraction over the Provisional Landsat 8 Surface Reflectance product and Landsat 8 image, respectively), one $R_{r s}$ spectra for the dark pixel (obtained from HydroLight), and one radiance spectra for the dark pixel (obtained from the statistics of a ROI over water in the Landsat 8 image). These spectra are used by the MoB-ELM to atmospherically correct the Landsat 8 image using the ENVI Classic software (RSI, 2004). This is performed using the "Empirical Line" algorithm of the "Calibration Utilities" in ENVI classic, where the Landsat 8 image is used as the input image, and the $R_{r s}$ spectra are labeled as "field spectra" and the radiance spectra are labeled as "data spectra." The final product of this process is an image in $R_{r s}$ values for each water pixel, which will be used to perform the retrieval of CPAs concentrations 


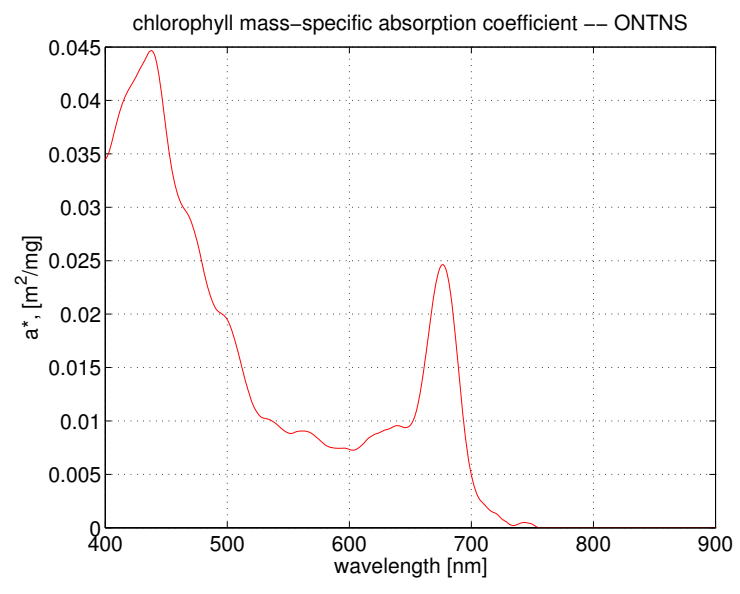

(a)

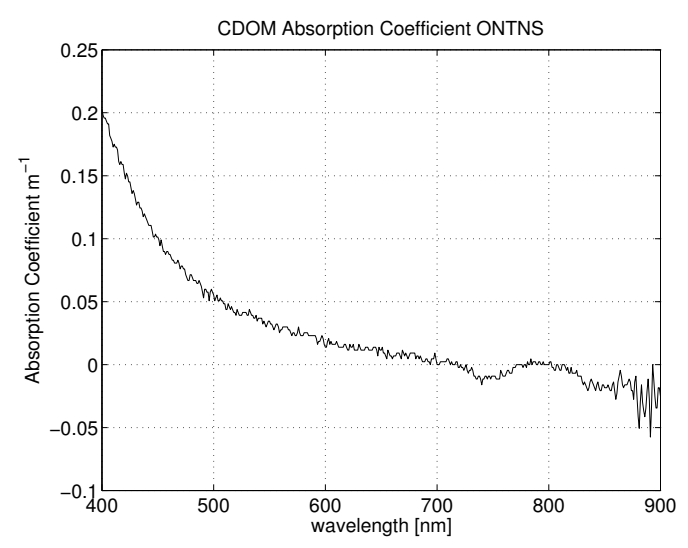

(c)

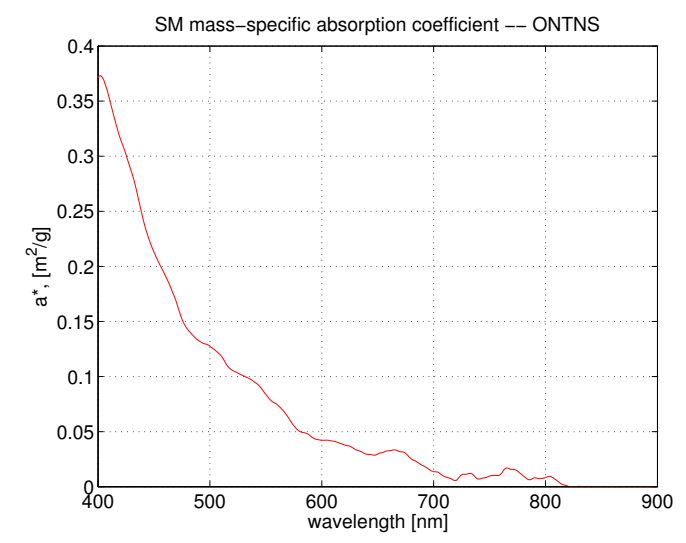

(e)

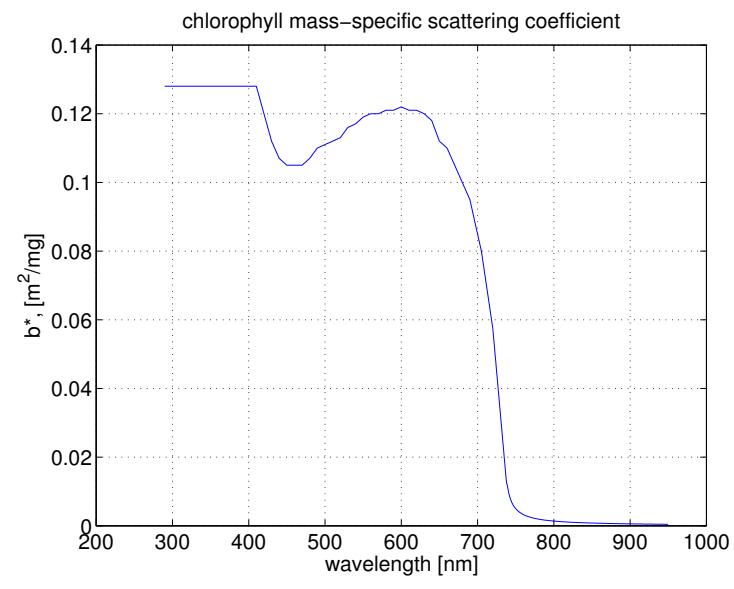

(b)

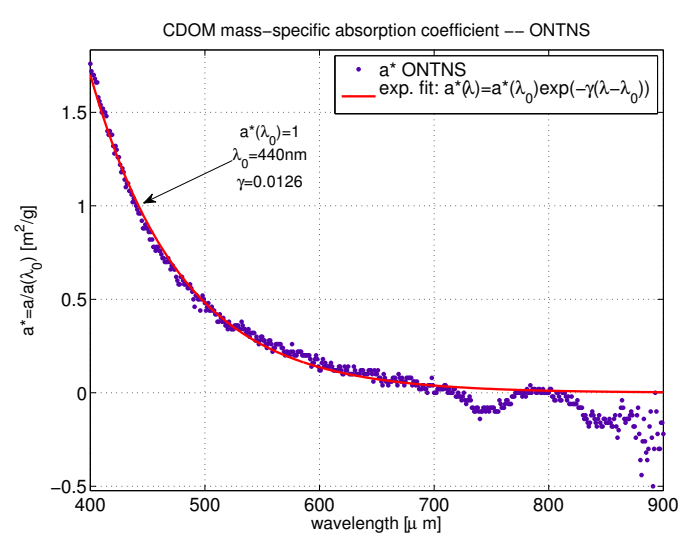

(d)

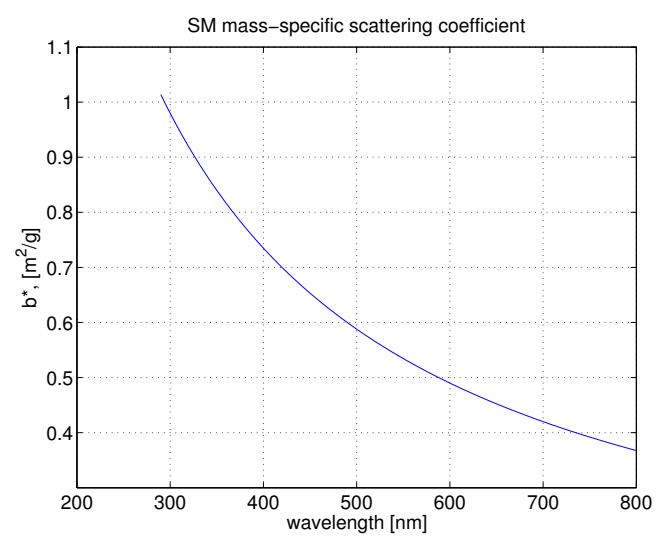

(f)

Figure 8: IOPs used for the determination of the $R_{r s}$ spectra of the dark pixel in Ecolight. Chlorophyll massspecific (a) absorption and (b) scattering coefficient spectra. CDOM absorption (c) and mass-specific absorption (d) coefficient spectra. Suspended Matter mass-specific absorption (e) and scattering (f) coefficient spectra. 
described in Section 2.4 below

\subsection{LUT Generation}

A LUT of $R_{r s}$ is generated in Ecolight for different combinations of CPA concentrations and scattering phase functions. Table 2 shows the different parameters used to create the LUT for the 2013 scene in Ecolight. The range of CPA concentrations was selected based on in situ and historical data from the water bodies in the scene. Ecolight was used in the same fashion as in the black pixel determination for the MoB-ELM (Section 2.2.2). In order to represent all the different kinds of waters in the scene in the LUT, two different sets of IOPs were used, one set for modeling the open lake conditions (low concentration of CPAs) based on the lab measurements for the ONTNS site, and another set for modeling the ponds condition (high concentration of CPAs) based on the lab measurements for the LONGS site. These IOPs are labeled in Table 2 as "ONTNS" for the open lake conditions and as "LONGS" for the ponds' conditions. Table 2 also shows the CPAs concentration used to create the LUT in Ecolight. Furthermore, different discretized Fournier-Forand phase functions with four different $b_{b} / b$ values (i.e. $0.5,1.0,1.5$ and $2.0 \%$ ) were used for the Chlorophyll- $a$ and SM scattering phase functions.

Table 2: Input parameters for the LUT generation in Ecolight for the Landsat 8 image acquired on 09-19-2013.

\begin{tabular}{ccccc}
\hline \hline IOPs Input & $\begin{array}{c}C_{a} \\
{\left[\mathrm{~m} \mathrm{~m}^{-3}\right]}\end{array}$ & $\begin{array}{c}\text { TSS } \\
{\left[\mathrm{g} \mathrm{m}^{-3}\right]}\end{array}$ & $\begin{array}{c}a_{C D O M}(440) \\
{[1 / \mathrm{m}]}\end{array}$ & $\begin{array}{c}b_{b} / b \\
{[\%]}\end{array}$ \\
\hline \hline \multirow{6}{*}{ ONTNS } & 0.1 & 1.0 & 0.11 & 0.5 \\
& 0.5 & 2.0 & 0.15 & 1.0 \\
& 1.0 & 5.0 & 0.21 & 1.4 \\
& 3.0 & 10.0 & 0.6 & 2.0 \\
& 10.0 & - & - & - \\
& 20.0 & - & - & - \\
LONGS & 40.0 & - & - & - \\
\hline \hline & 60.0 & 25.0 & 1.0 & 0.5 \\
& 90.0 & 45.0 & 1.2 & 1.0 \\
& 110.0 & 50.0 & - & 1.4 \\
& 135.0 & - & - & 2.0 \\
\hline \hline
\end{tabular}

Then, the LUT of $R_{r s}$ obtained from Ecolight is spectrally sampled to the OLI's spectral response. As an example, the LUT created with the parameters shown in Table 2 in Ecolight for the Landsat 8 image acquired on 09-19-2013 is shown in Figure 9.(a). This particular LUT has 
1170 elements spectrally sampled to the OLI's spectral response.

\subsection{Retrieval Algorithm}

The retrieval is divided into two stages. The first one uses the root mean squared error (RMSE) to fix the IOP set (ponds or lake) and the phase function. The RMSE is calculated between the water pixel and each element in the LUT, and the one with the smallest RMSE is selected as the first candidate. The IOP set and the phase function associated with this candidate are chosen as the IOP set and the phase function for the water pixel.

The second stage of the retrieval uses a non-linear optimization to estimate the CPA concentrations of the water pixel. Only the elements in the LUT with the same IOP set and phase function selected from the first stage are utilized in this stage. The water pixel is input to a non-linear optimization routine to estimate the CPA concentration through a trilinear interpolation within the LUT's elements. This method gives continuous concentration values. The RMSE and the non-linear optimization are described below.

\subsubsection{Root Mean Square Error}

In this work, the RMSE is defined as

$$
\operatorname{RMSE}(i)=\sqrt{\frac{1}{m} \sum_{1}^{m}\left[\widetilde{R}_{r s}\left(i, \lambda_{m}\right)-R_{r s}\left(\lambda_{m}\right)\right]^{2}}
$$

where $\widetilde{R}_{r s}\left(i, \lambda_{m}\right)$ is the $i$ th database spectrum from the LUT at wavelength band $m$ and $R_{r s}\left(\lambda_{m}\right)$ is the spectrum for a particular water pixel from the image.

\subsubsection{Non-linear Optimization}

The spectral matching is made by a least square error minimization algorithm using the "lsqnonlin" package of the MATLAB's Optimization Toolbox. Isqnonlin solves least-squares problems, including nonlinear data-fitting problems (Mathworks, 2014). If $f(x)$ is a user-defined 
vector function defined as

$$
f(x)=\left[\begin{array}{c}
f_{1}(x) \\
f_{2}(x) \\
\vdots \\
f_{m}(x)
\end{array}\right],
$$

with $x$ a vector. lsqnonlin tries to minimize the function

$$
\min _{x}\|f(x)\|_{2}^{2}=\min _{x}\left(f_{1}(x)^{2}+f_{2}(x)^{2}+f_{3}(x)^{2}+\ldots+f_{m}(x)^{2}\right)
$$

In this case, $x$ includes the three CPA concentrations and the function $f(x)$ is the difference between the water spectra $R_{r s}$ for each pixel and an estimated curve $F$ from the LUT, this is

$$
f=R_{r s}-F
$$

where $F$ is obtained from a trilinear interpolation based on the CPA concentrations of the LUT. The dimension $m$ is the number of bands. In other words, for each pixel in the image, Isqnonlin tries to find a function that minimizes the error between the measured value and an interpolated spectra from the LUT. Isqnonlin stops the search after reaching a certain threshold.

The output of this process is a concentration mapping for each water constituent that spans the range of constituent levels in the scene.

\subsection{Ground Truth Data Collection and Lab Measurements}

Field measurements were collected to support this study. Water samples were collected for each site in dark Nalgene bottles. Additionally, $R_{r s}$ spectra were measured using an SVC instrument (SVC, 2012) following the procedures suggested by Mobley (1999) and Mueller \& Austin (1995). Location for each site was recorded using a GPS. After collection, these water samples were analyzed in the lab at the Rochester Institute of Technology (RIT), and concentration and IOPs for each CPA were measured following the procedures described by Mitchell et al. (2002). These measurements are utilized as input to Ecolight for the LUT generation of the retrieval process and the black pixel determination for the MoB-ELM atmospheric correction algorithm. Also, some are utilized for 
validation of the retrieval process. The $C_{a}$ and $T S S$ measurements were validated by comparing with measurements analyzed by a credible lab (Monroe County Environmental Laboratory). This comparison between labs showed agreement in the measurements for a total of 71 samples with a $R^{2}=0.97$ and $R^{2}=0.78$ for $C_{a}$ and $T S S$, respectively (Concha, 2015).

\section{Results and Discussion}

The MoB-ELM atmospheric correction algorithm discussed above was applied to the Landsat 8 scene collected on 09-19-2013 (scene LC80160302013262LGN00) over the Rochester Embayment (latitude: $43^{\circ} 15^{\prime} 32.5^{\prime \prime} \mathrm{N}$ and longitude: $77^{\circ} 36^{\prime} 13.1^{\prime \prime} \mathrm{W}$ ) shown in Figure 1 and Figure 7 . This area of study was chosen because it included different water bodies with a wide range of CPAs characteristics, which helps to test the retrieval algorithm over unlike scenarios. These water bodies include ponds (Long Pond and Cranberry Pond) with high concentration of CPAs and Lake Ontario with low concentration of CPAs. As an example of the MoB-ELM results, Figure 9. (b) shows the $R_{r s}$ spectrum for four different stations of the 09-19-2013 Landsat 8 scene (Figure 7). The shape of these spectra resemble $R_{r s}$ of water pixels. Also, the spectrum corresponding to low concentration of CPAs (i.e. ONTOS: Lake Ontario off-shore and ONTNS: Lake Ontario near-shore) can be distinguished from the rest of the spectrum corresponding to higher concentration of CPAs (i.e. LONGS: Long Pond south, CRANB: Cranberry Pond).

After atmospherically correcting the Landsat 8 image, the retrieval of CPAs algorithm is applied to the area of study. The results of the retrieval for the 09-19-2013 scene are illustrated in the left-hand side of Figure 10 as a concentration map for each CPA. These maps exhibit the expected trend of low concentrations in the lake and higher concentrations in the ponds. The right-hand side of Figure 10 shows a comparison between measured concentration from the field and retrieved concentration obtained from the retrieval for each CPA for the different sites in the area of study for this particular date. The dashed line represents the 1:1 line. Note that the mixed patterns observed in the lake are likely caused by a whitening event reported on August and September of 2013.

A second image acquired on 09-29-2014 (scene LC80170302014272LGN00) was processed using 


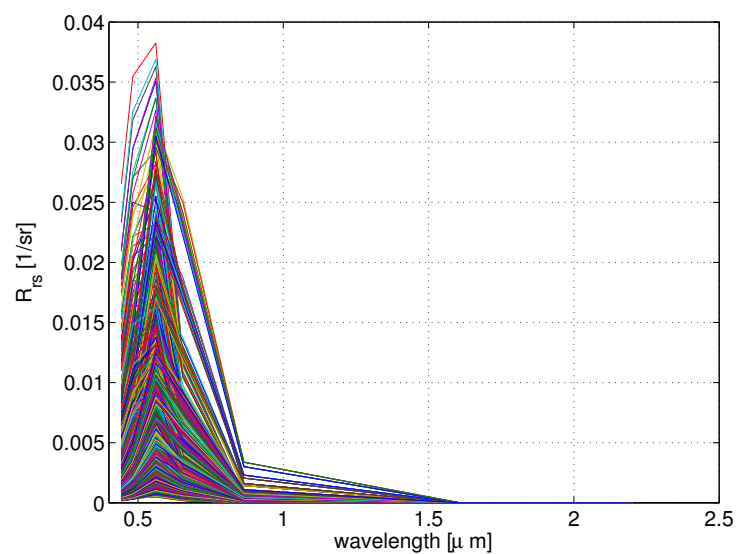

(a)

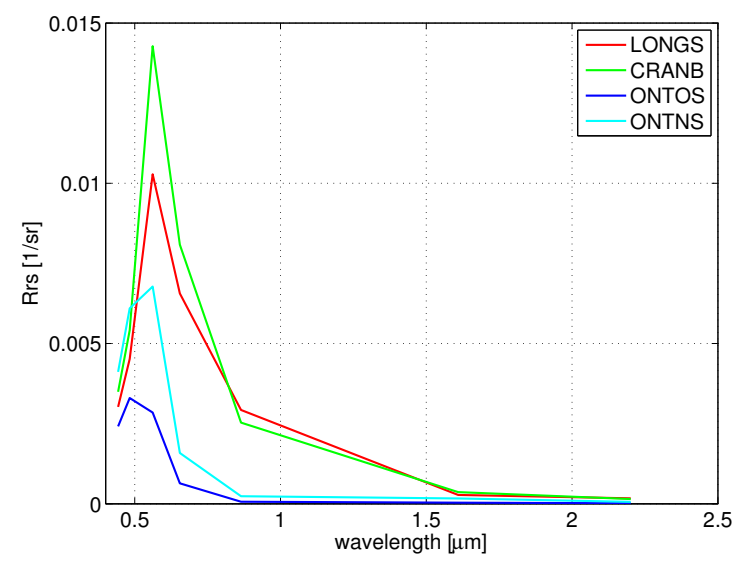

(b)

Figure 9: Spectral $R_{r s}$ used in the retrieval algorithm. (a) LUT with 1170 elements created in Ecolight for the Landsat 8 scene acquired on 09-19-2013. Each element was created from a combination of parameters in Table 2 . (b) $R_{r s}$ for the sites for the 09-19-2013 collection after applying the MoB-ELM atmospheric correction (Labels: LONGS: Long Pond south, CRANB: Cranberry Pond, ONTOS: Lake Ontario off-shore, and ONTNS: Lake Ontario near-shore)

the alternative method mentioned in $\S 2$. In this case, the bright pixel target is generated from an Ecolight run simulating the Cranberry Pond, which is the most eutrophic pond, and therefore, the brightest water pixel. The concentration maps for this second scene are illustrated in the left-hand side of Figure 11 again showing reasonable patterns in the lake and ponds. Finally, a third image was processed in a similar fashion to the 2013 image and the results are shown in the right-hand side of Figure 11. Note that glint effects were not specifically compensated for in the atmospheric correction process and future efforts using the urban region bright target approach will need to compensate for glint when it is present.

Figure 12 shows the comparison between predicted and observed values for all sample sites from the three scenes, along with a regression line fitted to the data and its respective goodness of fit values. The $R^{2}$ value of the regression for all CPAs are high for a total of $N=14$ samples. Note that dark targets on all days and the bright target on the 2014 date are forced to match by the MoB-ELM process. The results are very encouraging showing good quantitative agreement across a very wide range of concentrations. Note that the purpose of the relations shown in Figure 12 are exclusively for determining agreement between in situ and retrieved data, and these relations were not used for the retrieval. 


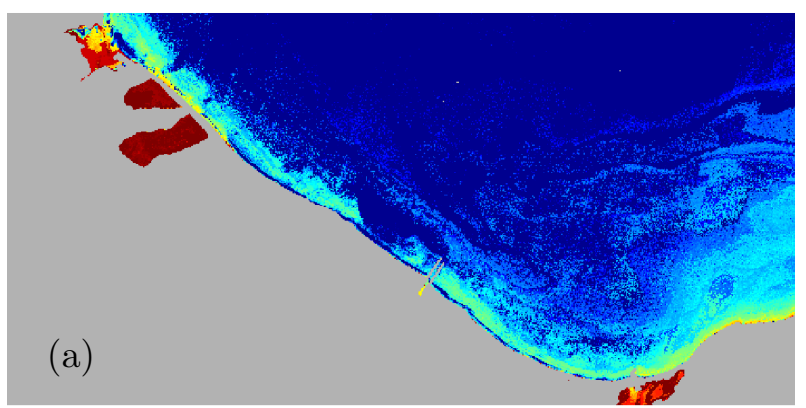

L8 retrieved $\mathrm{C}_{\mathrm{a}}\left[\mathrm{mg} \mathrm{m}^{-3}\right]$
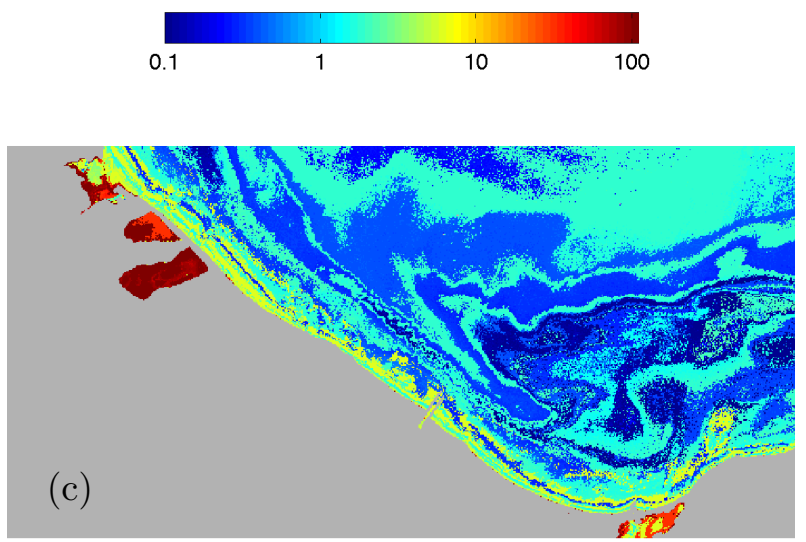

L8 retrieved TSS $\left[\mathrm{g} \mathrm{m}^{-3}\right]$
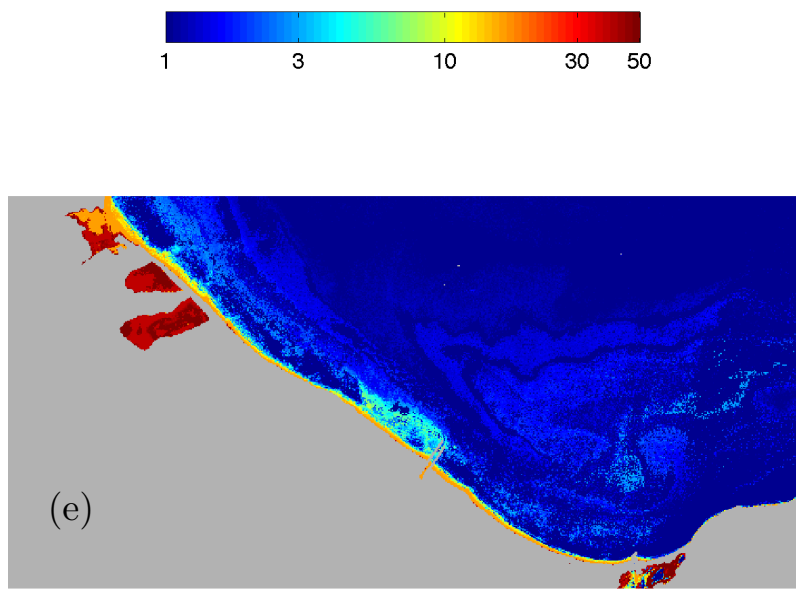

L8 retrieved $\mathrm{a}_{\mathrm{CDOM}}(440 \mathrm{~nm})[1 / \mathrm{m}]$

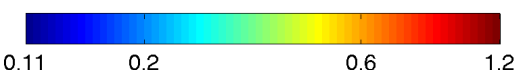

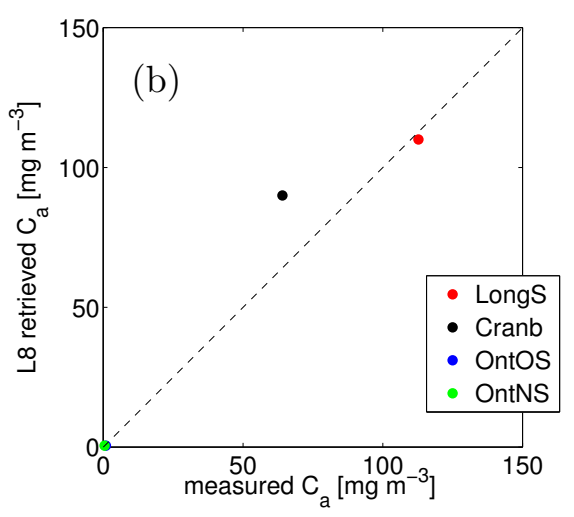
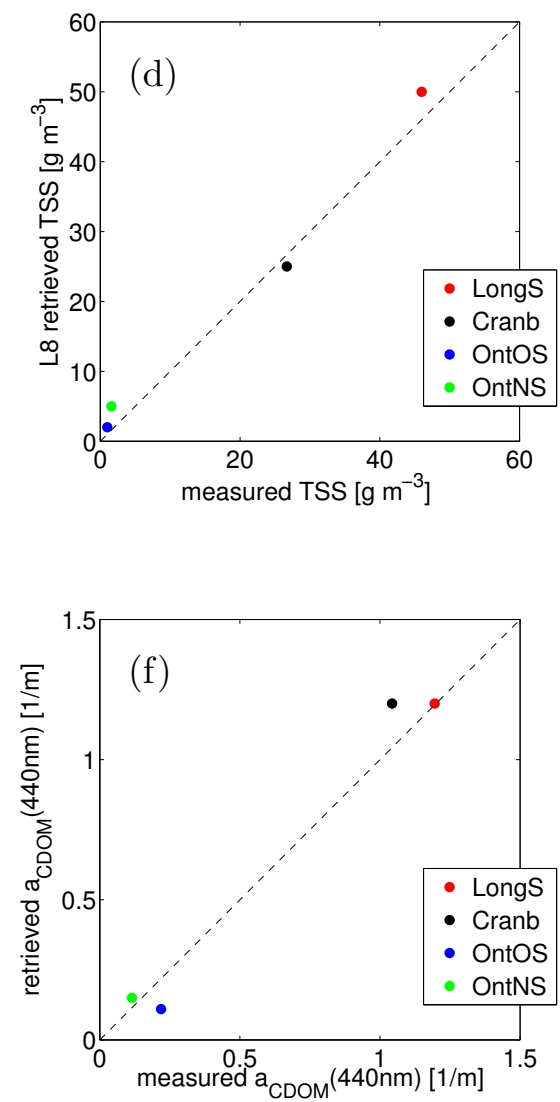

Figure 10: CPA retrieval results for the Landsat 8 image acquired on 09-19-2013 (scene LC80160302013262LGN00). Concentration maps in log scale (left) and measured versus retrieved plots (right) for (a,b) $C_{a},(\mathrm{c}, \mathrm{d})$ TSS and (e,f) CDOM. The dashed line represent the 1:1 line. (Labels: LongS: Long Pond south, Cranb: Cranberry Pond, OntOS: Lake Ontario off-shore, and OntNS: Lake Ontario near-shore).

The numerical results are summarized in Figure 13 where the root mean squared error (RMSE) 

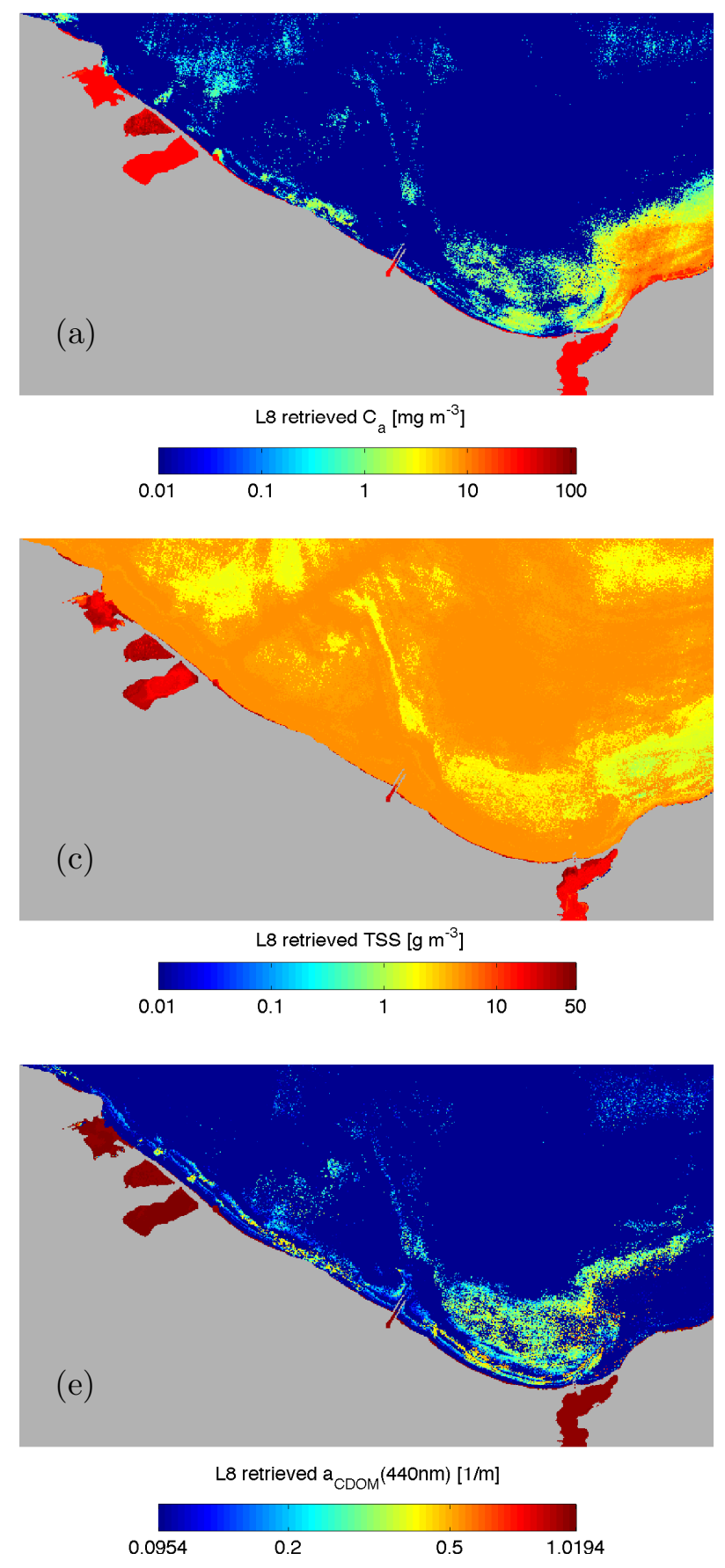
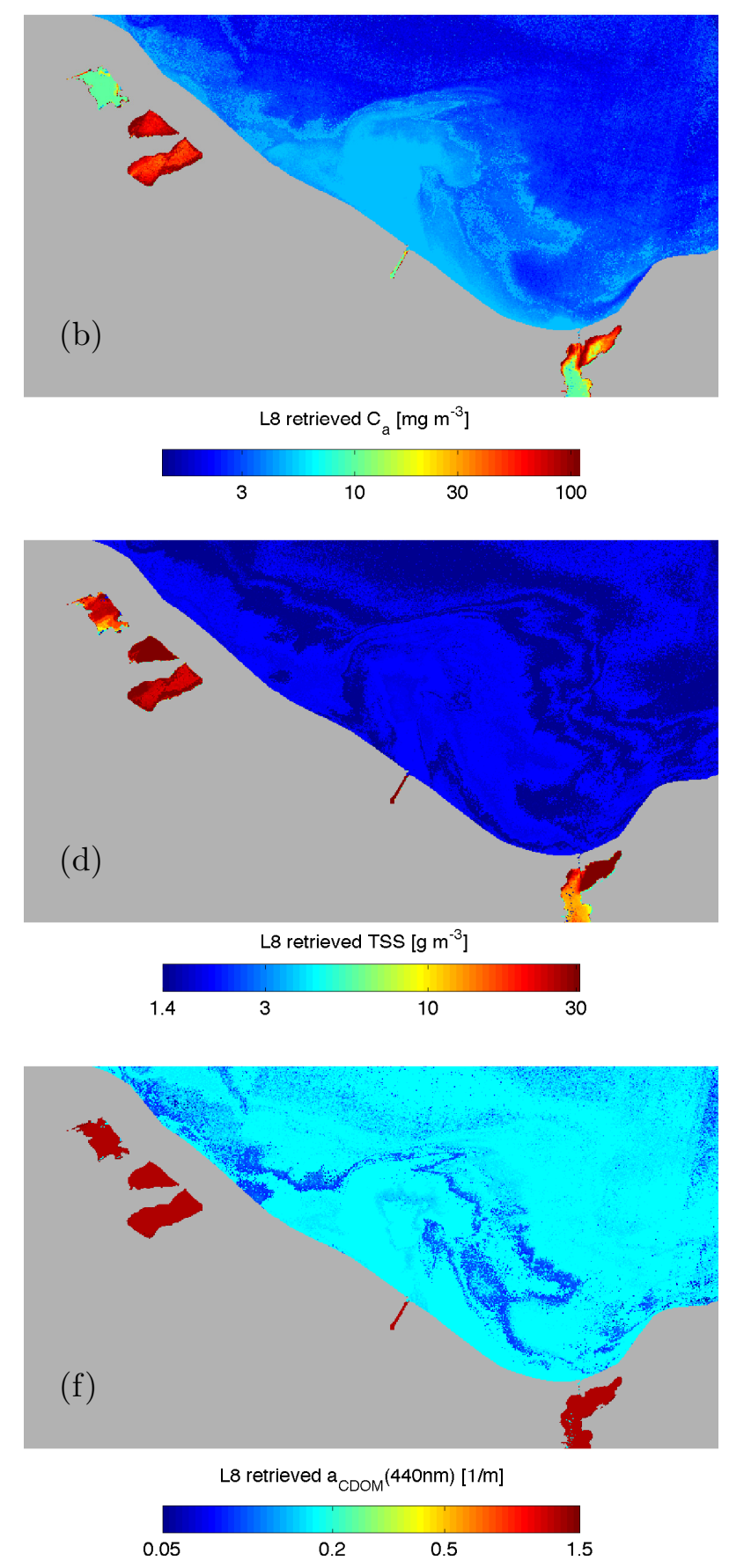

Figure 11: CPA concentration maps in log scale for Landsat 8 image acquired on 09-29-2014 (scene LC80170302014272LGN00) (left) and 09-16-2015 (scene LC80170302015259LGN00) (right) over the Rochester Embayment for $(\mathrm{a}, \mathrm{b}) C_{a},(\mathrm{c}, \mathrm{d})$ TSS and $(\mathrm{e}, \mathrm{f})$ CDOM.

performance, i.e. the normalized RMSE (NRMSE) for the CPA concentration, is defined as

$$
N R M S E=\frac{\sqrt{\frac{1}{N} \sum_{n=1}^{N}\left[C_{r e t}(n)-C_{\text {mea }}(n)\right]^{2}}}{\max \left\{C_{\text {mea }}(n) \text { \% } 4-\min \left\{C_{\text {mea }}(n)\right\}\right.} \times 100[\%]
$$




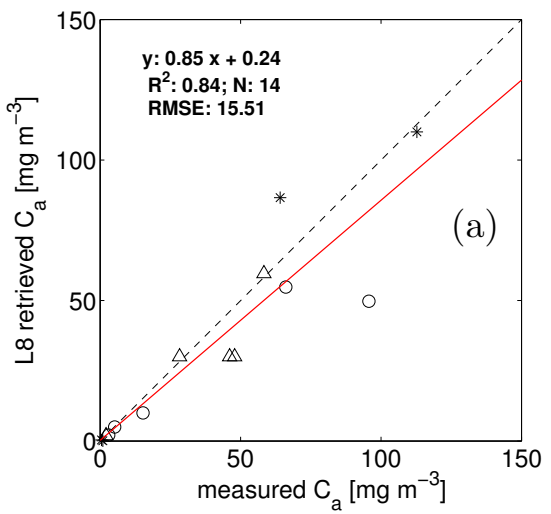

where $C_{r e t}$ is the retrieved CPA concentration (i.e. $C_{a}, T S S$ or $\left.a_{C D O M}(440 \mathrm{~nm})\right), C_{m e a}$ is the measured CPA concentration, and $n=1, \ldots, N$ is the $n$th site from a total of $N$ sites for all days. The NRMSE values are approximately $14 \%$ for $C_{a}, 11 \%$ for $T S S$, and about $7 \%$ for $a_{C D O M}(440 \mathrm{~nm})$.

These errors are consistent with the expected errors reported by Gerace et al. (2013).

Figure 12: Landsat 8's retrieved vs measured CPA concentration for the 09-19-2013 (*), 09-29-2014 ( $\triangle$ ), and 09-162015 (o) scenes with regression line (solid red line) and goodness of fit values for (a) chlorophyll, (b) sediments, and

(c) CDOM. The dashed line represents the 1:1 line.

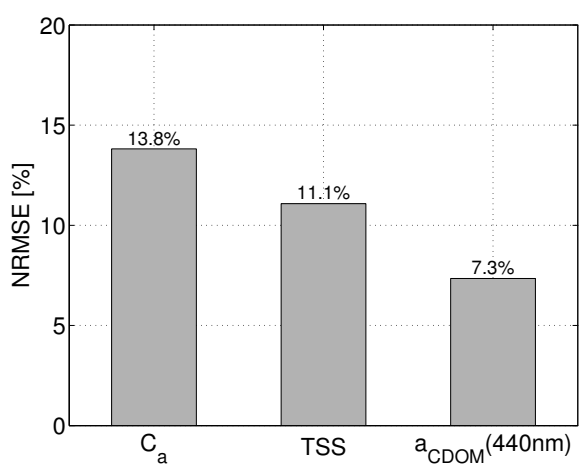

Figure 13: NRMSE for each CPA for the 09-19-2013, 09-29-2014 and 09-16-2015 scenes.
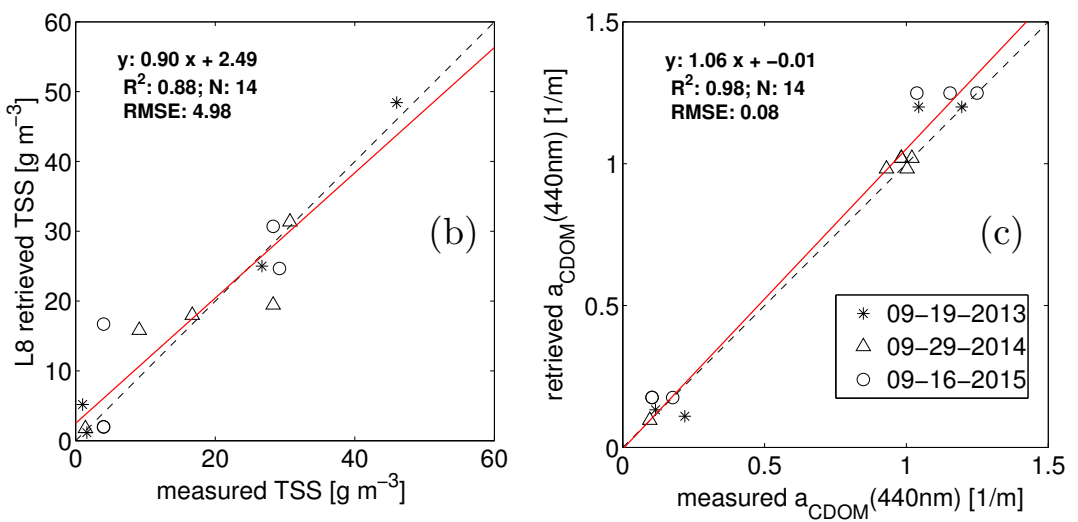

\section{Conclusions}

This work presented a CPA retrieval using Landsat 8 data based a spectrum matching and LUT approach. The retrieval results shown in this study are promising for the use of Landsat 8 for monitoring of coastal and inland waters. The retrieval process was applied to three Landsat 8 scenes over the same study area and compared with field measurements. Maps of CPA concentrations show 
the expected trends of low concentration in the lake and higher concentration in the ponds. The retrieval was validated with ground-truth data taken at the same time as the satellite overpass. The comparison with field measurements exhibit error comparable with previous performance predictions for Landsat 8 (Gerace et al. 2013). An advantage of this retrieval algorithm is that it retrieves simultaneously all three CPAs. This is accomplished because every combination of CPAs has associated a unique spectral $R_{r s}$ generated in Ecolight.

The MoB-ELM atmospheric correction algorithm presented here tries to avoid the use of field reflectance ground-truth as commonly used in the traditional ELM method. In the MoB-ELM, the bright pixel is obtained from either the Landsat reflectance product over a bright target in the scene or from an Ecolight run simulating a water body with high concentration of CPAs in the scene. The dark pixel is obtained from an Ecolight run simulating a water body with low concentration of CPAs present in the scene. This algorithm does not require zero water signal in the NIR bands, so it could be applied to highly turbid waters. This algorithm assumes that the atmosphere is the same and uniform over the area of study.

One limitation of the developed retrieval algorithm is that the MoB-ELM and the LUT generation need some knowledge of the water body (e.g. in situ IOPs and concentration of constituents at at least one point), which is often available but not always, and therefore, it will not work in every case because of the need for this knowledge. However, it is still a good answer for many cases where this knowledge is indeed available. Future work is aiming for an approach with good atmospheric correction without the need for ground-truth. For example, IOPs are often stable and could be estimated from previous studies (perhaps seasonally in some water bodies), and CPAs of a local open water region may be predicted based on historical data if no concurrent data are available. However, a more in depth analysis of how stable the IOPs of a certain region are over time is needed. The accuracy of the retrieval depends on the robustness of the field-based library (LUT) and a global application could be possible if this LUT is comprehensive enough. To accomplish this, a wider range of water bodies have to be included in the dataset, and a study of how the IOPs vary from region to region is needed.

Some pixels from the lake shoreline include signal from the bottom causing outliers in the 
retrieval results since the bottom reflectance was not accounted for in the process. The next version of this retrieval algorithm should address this issue. Glint and adjacency effects were also not addressed in this work, and they could affect the atmospheric correction.

For further validation, this method needs to be applied to more scenes over the same area of study or to a different area of study where sufficient ground-truth data are available to increase the number of samples to be compared. Additionally, the results from the MoB-ELM and the retrieval algorithm will be compared with standard products derived from ocean color satellites (NASA OBPG standard ocean color products).

To date, there are no other sources of free access, open to the international science community, satellite imagery with similar spatial resolution or similar standard product (e.g. MODIS chl-a product) to compare with Landsat 8 . Therefore, a direct comparison of results from our approach with typical algorithms over water bodies smaller than one kilometer is not possible. This is a challenge that needs to be addressed since there is a particular interest from local communities for monitoring water bodies that are not resolvable by current ocean color satellites due to coarse spatial resolution. This is the case of the ponds included in this study, which are less than one kilometer in size. This fact makes Landsat 8 a step forward in the retrieval of water quality parameters over medium to small water bodies. This also opens a need for more field measurement collection (i.e. IOPs, $R_{r s}$ and concentrations) on a regular basis where water quality needs to be assessed for the validation of products derived from moderate spatial resolution sensors such as Landsat 8 and Sentinel 2.

Landsat 8's radiometric resolution, new coastal and cirrus band, slightly narrower bands, and improved SNR allow a better retrieval of water quality information from inland and coastal water compared with its predecessors, i.e. Landsat 1-7. The authors also recognize that its 16-day repeat coverage and the lack of a red edge band suitable for phycocyanin still pose major limitations for its operational use in water studies. However, Landsat 8 is definitely preparing the path for future missions with high spatial resolutions. 


\section{Acknowledgments}

The authors would like to extend a special thanks to the United States Geological Survey (USGS) for its sponsorship (contract number G12PC00065) that has made this effort possible. Special thanks to the Monroe County Environmental Laboratory of the Monroe County Department of Environmental Services for the $C_{a}$ and TSS measurements used to validate our in house concentration measurements. Nina Raqueño is thanked for her invaluable help in the logistic of the field data collections, and faculty, staff and students at the Rochester Institute of Technology for helping in the data collection, especially Paul Romanczyk and Rolando Raqueño. Also, thanks to Dr. Christy Tyler for facilitating the Aquatic Ecology Lab at RIT for the $C_{a}$ measurements.

\section{References}

Concha, J. A. (2015). The Use of Landsat 8 for Monitoring of Fresh and Inland Waters. Ph.D. thesis Rochester Institute of Technology.

Concha, J. A., \& Schott, J. R. (2014a). A model-based ELM for atmospheric correction over Case 2 water with Landsat 8. In Ocean Sensing and Monitoring VI SPIE Proceedings. SPIE.

Concha, J. A., \& Schott, J. R. (2014b). In-water component retrieval over case 2 water using landsat 8: Initial results. Geoscience and Remote Sensing Symposium (IGARSS), 2014 IEEE International, (pp. 4458-4461). doi:10.1109/IGARSS.2014.6947481

Esaias, W., Abbott, M., Barton, I., Brown, O. B., Campbell, J., Carder, K., Clark, D., Evans, R., Hoge, F. E., Gordon, H., Balch, W., Letelier, R., \& Minnett, P. (1998). An overview of modis capabilities for ocean science observations. Geoscience and Remote Sensing, IEEE Transactions on, $36,1250-1265$. doi:10.1109/36.701076.

Franz, B. A., Bailey, S. W., Kuring, N., \& Werdell, P. J. (2015). Ocean color measurements with the operational land imager on landsat-8: implementation and evaluation in seadas. Journal of Applied Remote Sensing, 9, 096070-096070. URL: http://dx.doi.org/10.1117/1.JRS.9. 096070 .

Gerace, A. D., \& Schott, J. R. (2012). Over-water atmospheric correction for landsat's new oli sensor. In Conference on Ocean Sensing and Monitoring IV. Proceedings of SPIE. 
Gerace, A. D., Schott, J. R., \& Nevins, R. (2013). Increased potential to monitor water quality in the near-shore environment with Landsat's next-generation satellite. Journal of Applied Remote Sensing, .

Gordon, H. R. (1997). Atmospheric correction of ocean color imagery in the earth observing system era. Journal of Geophysical Research-Atmospheres, 102, 17081-17106. URL: <GotoISI>://WOS: A1997XN38400049, doi:10.1029/96jd02443

Gordon, H. R., \& Wang, M. (1994). Retrieval of water-leaving radiance and aerosol optical thickness over the oceans with seawifs: a preliminary algorithm. Appl. Opt., 33, 443-452.

IJC (1980). Phosphorus Management for the Great Lakes: Final Report of the Phosphorus Management Strategies Task Force. Technical Report International Joint Commission's Great Lakes Water Quality Board and Great Lakes Science Advisory Board.

Irons, J. R., Dwyer, J. L., \& Barsi, J. A. (2012). The next Landsat satellite: The Landsat Data Continuity Mission. Remote Sensing of Environment, 122, 11 - 21.

Makarewicz, J. C. (2000). New York's North Coast a Troubled Coastline: Lake Ontario Embayments Initiative. Technical Report The College of Brockport.

Makarewicz, J. C., \& Lampman, G. G. (1994). Water Quality of Long, Cranberry, Buck and Round Ponds 1993 -1994. Technical Report The College of Brockport.

Mathworks (2014). Matlab documentation. URL: http://www .mathworks.com/help/

McClain, C. R., Feldman, G. C., \& Hooker, S. B. (2004). An overview of the seawifs project and strategies for producing a climate research quality global ocean bio-optical time series. Deep Sea Research Part II: Topical Studies in Oceanography, 51, 5 - 42. URL: http: //www.sciencedirect.com/science/article/pii/S0967064504000037, doi/http://dx.doi. org/10.1016/j.dsr2.2003.11.001. Views of Ocean Processes from the Sea-viewing Wide Fieldof-view Sensor (SeaWiFS) Mission: Volume 1.

Mitchell, B. G., Kahru, M., Wieland, J., \& Stramska, M. (2002). Chapter 4: Determination of spectral absorption coefficients of particles, dissolved material and phytoplankton for discrete water samples. In J. L. Mueller, G. S. Fargion, \& C. R. McClain (Eds.), Ocean Optics Protocols For Satellite Ocean Color Sensor Validation, Revision 4, Volume IV: Inherent Optical Properties: 
Instruments, Characterizations, Field Measurements and Data Analysis Protocols NASA/TM2003-211621/Rev4-Vol.IV. Goddard Space Flight Space Center.

Mobley, C. D. (1999). Estimation of the remote-sensing reflectance from above-surface measurements. Appl. Opt., 38, 7442-7455.

Mobley, C. D., \& Sundman, L. K. (2013a). Hydrolight 5.2/Ecolight 5.2: Technical Documentation. Sequoia Scientific, Inc.

Mobley, C. D., \& Sundman, L. K. (2013b). Hydrolight 5.2/Ecolight 5.2: Users' Guide. Sequoia Scientific, Inc.

Mobley, C. D., Sundman, L. K., Davis, C. O., Bowles, J. H., Downes, T. V., Leathers, R. A., Montes, M. J., Bisset, W. P., Kohler, D. D. R., Reid, R. P., Louchard, E. M., \& Gleason, A. (2005). Interpretation of hyperspectral remote-sensing imagery by spectrum matching and look-up tables. Applied Optics, 44, 3576-3592.

Mueller, J. L., \& Austin, R. W. (1995). SeaWiFS Technical Report Series - Volume 25, Ocean Optics Protocols for SeaWiFS Validation, Revision 1. Technical Report NASA Technica Memorandum 104566, Vol. 25 NASA.

NYSDEC (2010). Total Maximum Daily Loads (TMDLs) for Phosphorus in Buck, Long, and Cranberry Ponds. Technical Report The Cadmus Group Monroe County, New York.

NYSDEC (2015). Genesee River Basin: Nine Key Element Watershed Plan for Phosphorus and Sediment. Technical Report New York State Department of Environmental Conservation.

Pahlevan, N., Garrett, A. J., Gerace, A. D., \& Schott, J. R. (2012). Integrating Landsat-7 Imagery with Physics-based Models for Quantitative Mapping of Coastal Waters near River Discharges. PEERS, .

Patt, F., Barnes, R., Eplee, R., Franz, B., Robinson, W., Feldman, G., Bailey, S., Gales, P., Werdell, P., Wang, M., Frouin, R., Stumpf, R., \& Arnone, R. (2003). Algorithm Updates for the Fourth SeaWiFS Data Reprocessing. Report 2003-206892 NASA Goddard Space Flight Center.

Raqueño, R., Raqueño, N., Fairbanks, R., Schott, J., Vodacek, A., \& Hamel, J. (2000). Hyperspectral analysis tools for the multiparameter inversion of water quality factors in coastal regions. In Imaging Spectrometry VI. SPIE. 
Raqueño, R. V. (2003). Hyperspectral analysis tools for multiparameter inversion of water quality factors in the lake Ontario Rochester embayment. Thesis State University of New York, Syracuse. Roy, D. P., Wulder, M. A., Loveland, T. R., C. E., W., Allen, R. G., Anderson, M. C., Helder, D., Irons, J. R., Johnson, D. M., Kennedy, R., Scambos, T. A., Schaaf, C. B., Schott, J. R., Sheng, Y., Vermote, E. F., Belward, A. S., Bindschadler, R., Cohen, W. B., Gao, F., Hipple, J. D., Hostert, P., Huntington, J., Justice, C. O., Kilic, A., Kovalskyy, V., Lee, Z. P., Lymburner, L., Masek, J. G., McCorkel, J., Shuai, Y., Trezza, R., Vogelmann, J., Wynne, R. H., \& Zhu, Z. (2014). Landsat-8: Science and product vision for terrestrial global change research. Remote Sensing of Environment, 145, 154-172. URL: http://www.sciencedirect.com/science/article/pii/ S003442571400042X. doi:http://dx.doi.org/10.1016/j.rse.2014.02.001.

RSI (2004). ENVI User's Guide. Research System Incorporated.

Schott, J. R. (1997). Remote Sensing: The Image Chain Approach. New York, NY: Oxford University Press.

Schott, J. R., Salvaggio, C., \& Volchok, W. J. (1988). Radiometric scene normalization using pseudoinvariant features. Remote Sensing of Environment, . URL: http://www. sciencedirect.com/science/article/pii/0034425788901162, doi/http://dx.doi.org/10. 1016/0034-4257(88)90116-2.

SVC (2012). SVC HR-1024i / SVC HR-768i User Manual. Spectra Vista Corporation (rev. 1.5 ed.). URL: http://www.spectravista.com/.

USGS (2015). Provisional Landsat 8 Surface Reflectance Product. Technical Report USGS.

Vanhellemont, Q., \& Ruddick, K. (2014). Turbid wakes associated with offshore wind turbines observed with Landsat 8. REMOTE SENSING OF ENVIRONMENT, 145, 105-115. doi:\{10. $1016 / j \cdot r s e .2014 .01 .009\}$.

Vanhellemont, Q., \& Ruddick, K. (2015). Advantages of high quality swir bands for ocean colour processing: Examples from landsat-8. Remote Sensing of Environment, 161, 89-106. URL: http: //wWw.sciencedirect.com/science/article/pii/S0034425715000577, doi:http://dx.doi. org $/ 10.1016 / j . r s e .2015 .02 .007$

Wang, M. (2007). Remote sensing of the ocean contributions from ultraviolet to near-infrared using 
the shortwave infrared bands: simulations. Appl. Opt., 46, 1535-1547. 